\title{
Detail Solidworks Design and Simulation of an Unmanned Air Vehicle
}

\author{
Md. Shaiful islam ${ }^{1}$, Mohammad Mukit Hasan², Mir Md Al Kamah Tamal ${ }^{3}$, \\ Md. Jamal Mian ${ }^{4}$, Md. Touhidur Rahman Evan ${ }^{5}$ \\ 1, 2, 3, 4, 5(Aeronautical Engineering Department, Military Institute of Science \& Technology, Dhaka, \\ Bangladesh)
}

\begin{abstract}
Unmanned Air Vehicles (UAVS) are a new type of aircraft maturing day by day and have reached unprecedented levels of growth recently. Unmanned Air Vehicles (UAVS) have enormous potential in applications. They are deployed predominantly for military and special operation applications, but also used in a small but growing number of civil applications, such as policing and firefighting, and nonmilitary security work, such as surveillance of pipelines. UAVs are often preferred for missions that are too "dull, dirty, and dangerous" for manned aircraft. This article mainly describes the design process of an unmanned air vehicle in solidworks and shows the results of solidworks simulation analysis.

Keyword: Solidworks, simulation, airfoil, design, wing, control surface etc.
\end{abstract}

\section{Introduction:}

The First Unmanned Aerial Vehicles emerged in the mid-1990s [1] and since then have evolved very fast new designs have been smaller, more autonomous and of increased endurance. Recent advances in electrical and mechanical system miniaturization have spurred interest in finding new solutions to an array of military and civilian missions. Modern UAVs usually weigh between $50 \mathrm{~g}$ and $250 \mathrm{~g}$ and have a wingspan from 100 to 300 $\mathrm{mm}$. They are built primarily for reconnaissance missions, but as some market research [2] have shown; there are also other possible applications, both military and civilian, such as situational awareness or air sampling. Whereas scaling down is a huge problem due to aerodynamic problems (very low Reynolds numbers), miniaturization and development of electronic equipment allows UAVs to be less expensive and more versatile. In fact, Commercial, Off-The-Shelf (COTS) elements used today by RC modellers are suitable for micro aircraft use with very little weight penalty. At present, there are three types of UAVs [3, 4]: fixed-wing, rotorcraft and ornithopter (flapping wing). Ornithopters are less popular and still require further development to achieve performance similar to fixed-wing and rotorcraft types. Fixed-wing aircraft are able to fly fast and loiter over targets for observation. Rotorcraft type vehicles can hover above the target, providing constant observation. Hover capability also makes them superior to fixed-wing configurations in an environment that requires maneuvering close to obstacles like buildings and trees, but they are not able to perform fast dashes similarly to fixed wing planes. In case of design an unmanned air vehicle solidworks play an important role. In solidworks it is very easy to design than AutoCAD. Beside this solidworks can be used to perform static, thermal, frequency, buckling, drop test, pressure vessel design, fatigue etc.

\section{Steps of design and analysis:}

Design and analysis are consists of three very simple steps. Firstly initial sketch made by hand then detail design with all necessary component then simulation

Initial sketch
Detail design
Simulation

\section{Initial sketch:}

Initially there should be some paperwork on the idea of designing. It needs not to be $100 \%$ correct. It just for the help in time of design. The finalized initial design is a conventional aircraft, powered by a single tractor propeller and features a conventional tail that will take the landing loads at the bottom surface of the fuselage during grass landing. 


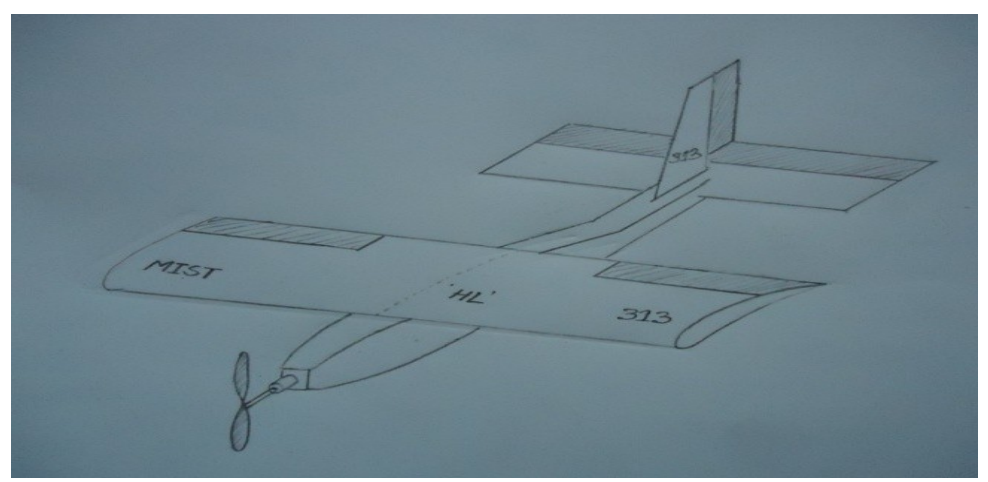

Detail design: Here various components of the aircraft have been shown along with the dimension. The drawing is done in 4 steps to make all parts visible and easily noticeable.
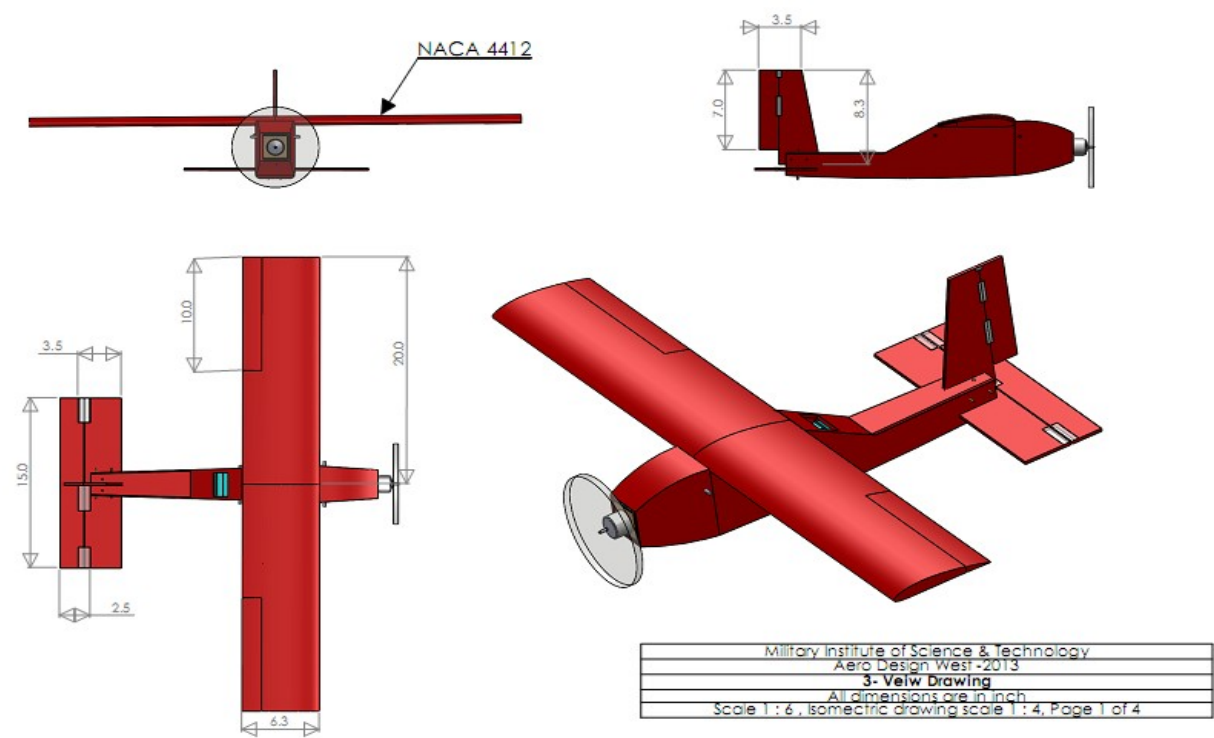

Figure 1: 3-Veiw drawing with dimensions

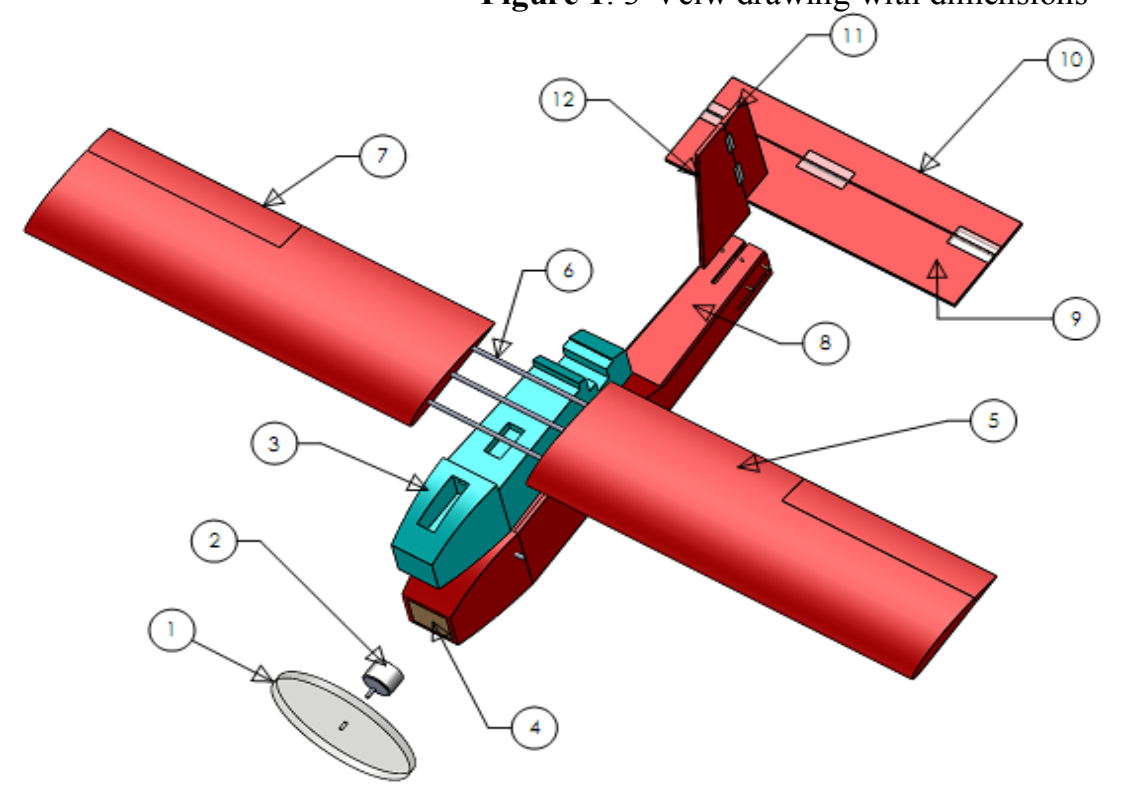

\begin{tabular}{|c|l|c|}
\hline $\begin{array}{c}\text { TEM } \\
\text { NO. }\end{array}$ & \multicolumn{1}{|c|}{ PART NUMBER } & QTY. \\
\hline 1 & Propeller & 1 \\
\hline 2 & Brushless motor & 1 \\
\hline 3 & $\begin{array}{l}\text { Fuseloge inside } \\
\text { portion }\end{array}$ & 1 \\
\hline 4 & $\begin{array}{l}\text { motor mounting } \\
\text { ply-wood }\end{array}$ & 1 \\
\hline 5 & Left Wing & 1 \\
\hline 6 & wing joining stick & 3 \\
\hline 7 & Left aileron & 1 \\
\hline 8 & $\begin{array}{l}\text { Fuselage rear } \\
\text { portion }\end{array}$ & 1 \\
\hline 9 & Horizontal tail & 1 \\
\hline 10 & Elevator & 1 \\
\hline 11 & Rudder & 1 \\
\hline 12 & Vertical tail & 1 \\
\hline
\end{tabular}

\begin{tabular}{|c|}
\hline Military Institute of Science \& Technology \\
\hline Component Veiw \\
\hline Scale $1: 4$ \\
\hline Page 2 of 4 \\
\hline
\end{tabular}

Figure 2: Component view with quantity 


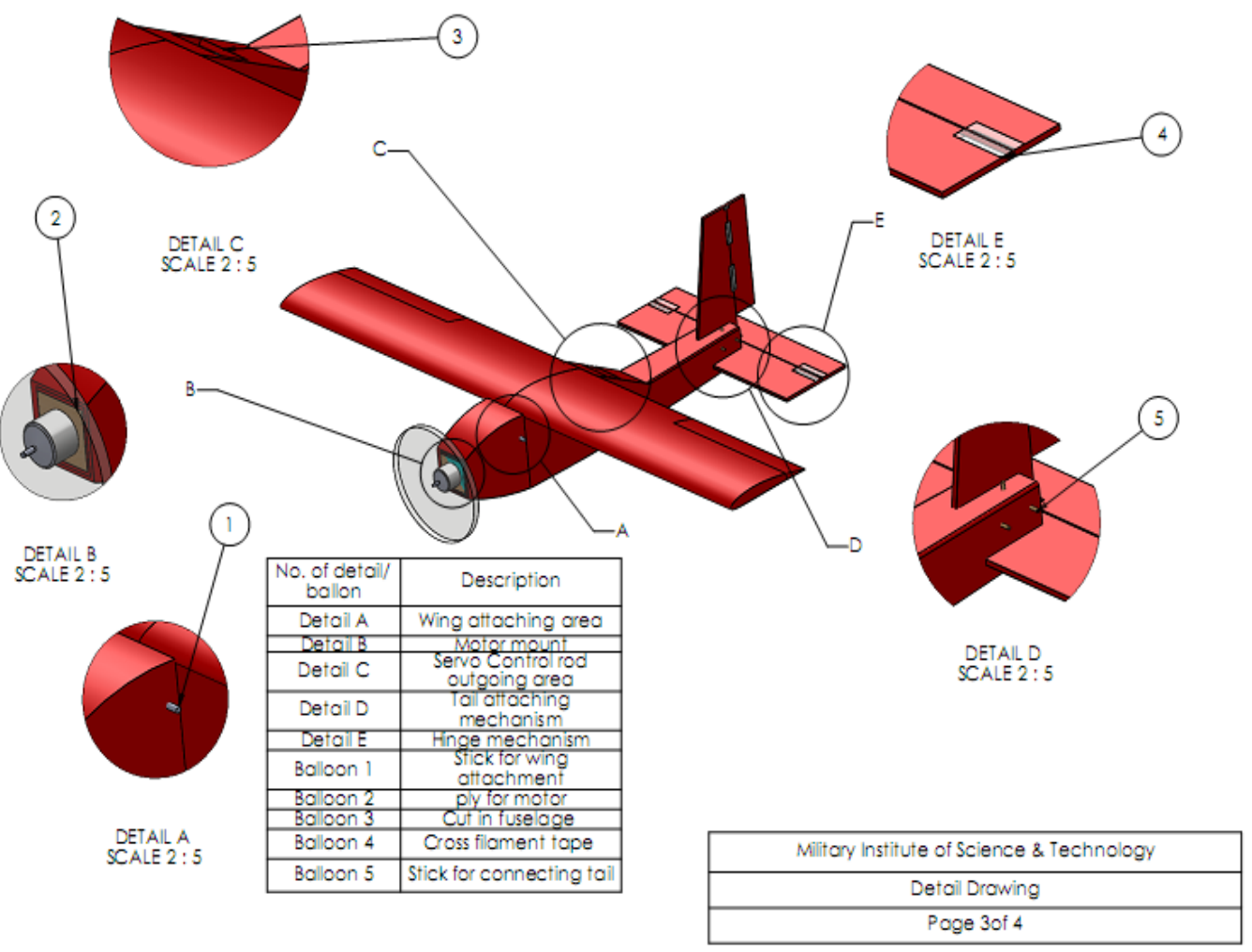

Figure 3: Detail drawing with connection

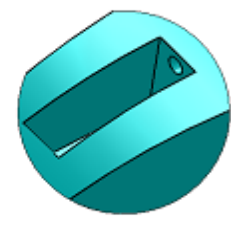

DETAIL C
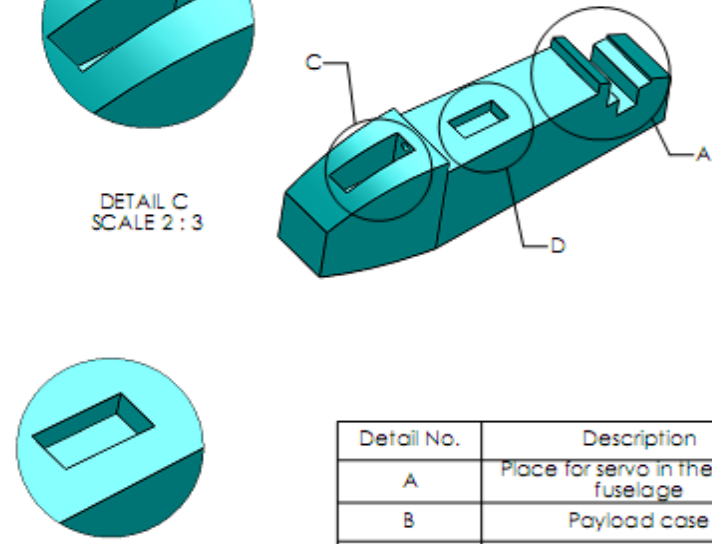

DEFALILD

\begin{tabular}{|c|c|}
\hline Detail No. & \begin{tabular}{c} 
Description \\
\hline A
\end{tabular} \\
\hline B & $\begin{array}{c}\text { Pace for servo in the inside } \\
\text { fuselage }\end{array}$ \\
\hline C & Placead cose \\
\hline D & Receiver locator \\
\hline E & Battery locator \\
\hline
\end{tabular}
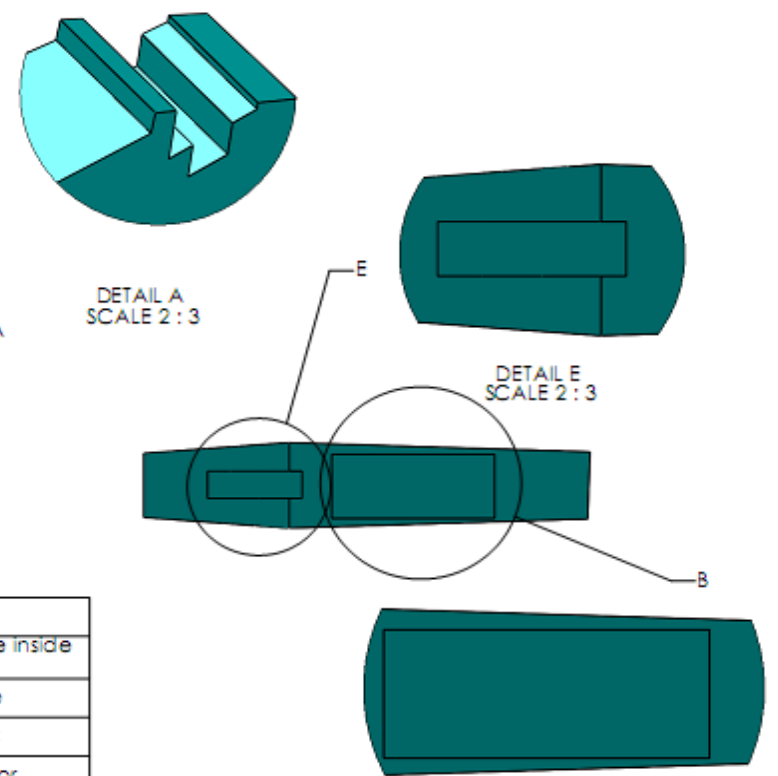

DETALIL B

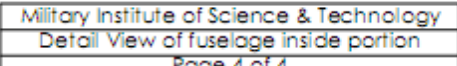

Figure 4: fuselage insight portion

Simulation: Solidworks simulation has been done on wing and horizontal tail, for determining stress, strain, and displacement. 


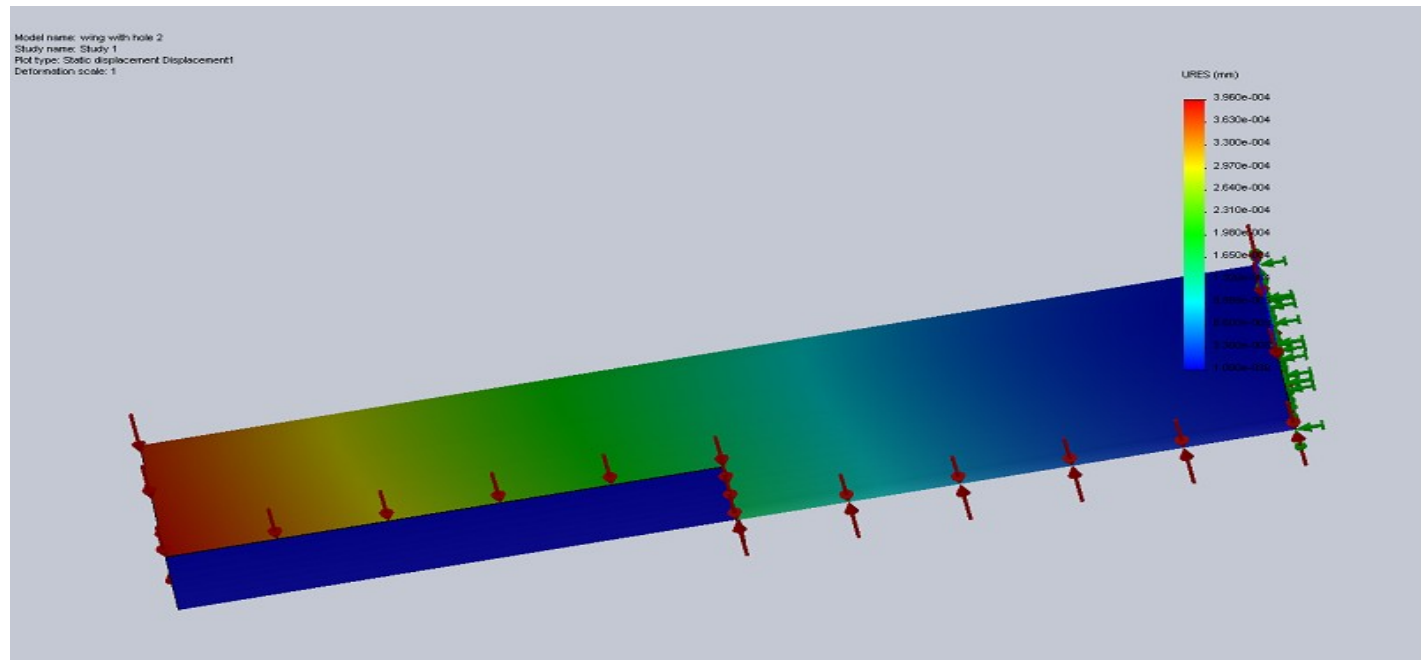

Figure 5: displacement analysis of wing

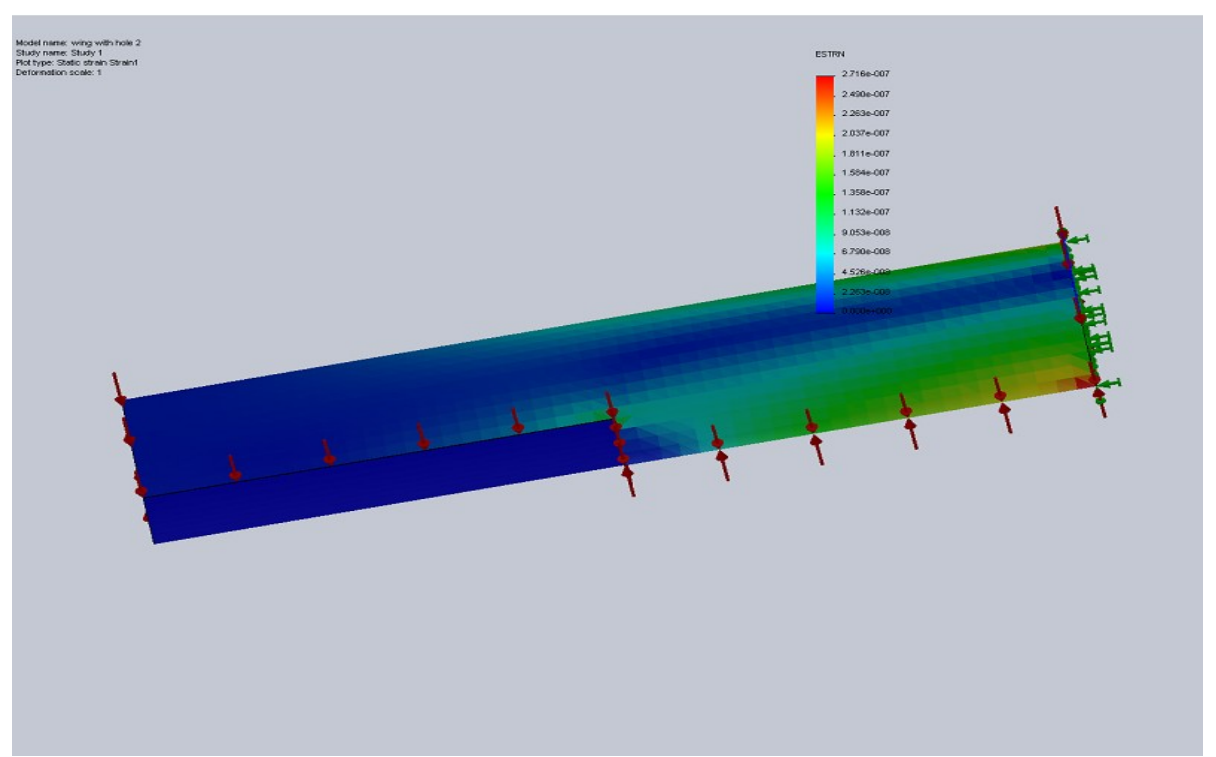

Figure 6: strain analysis of wing

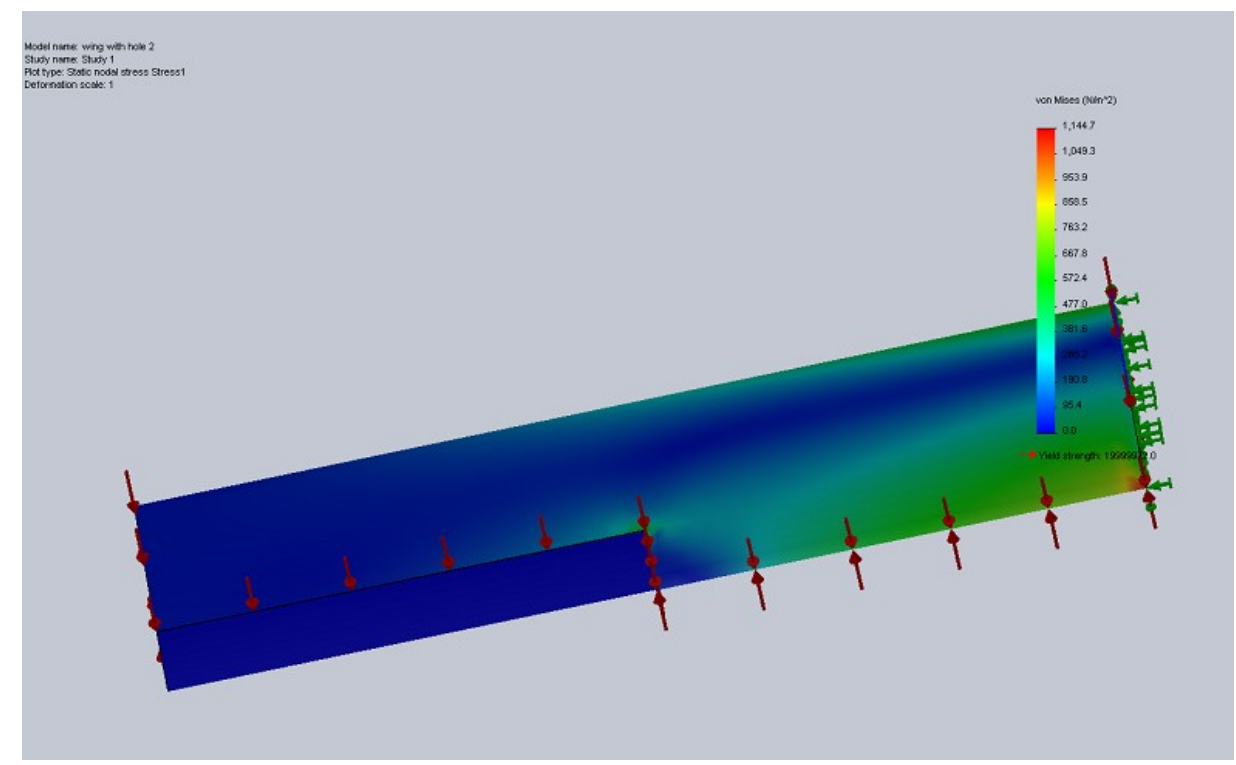

Figure 7: static nodal stress analysis of wing 


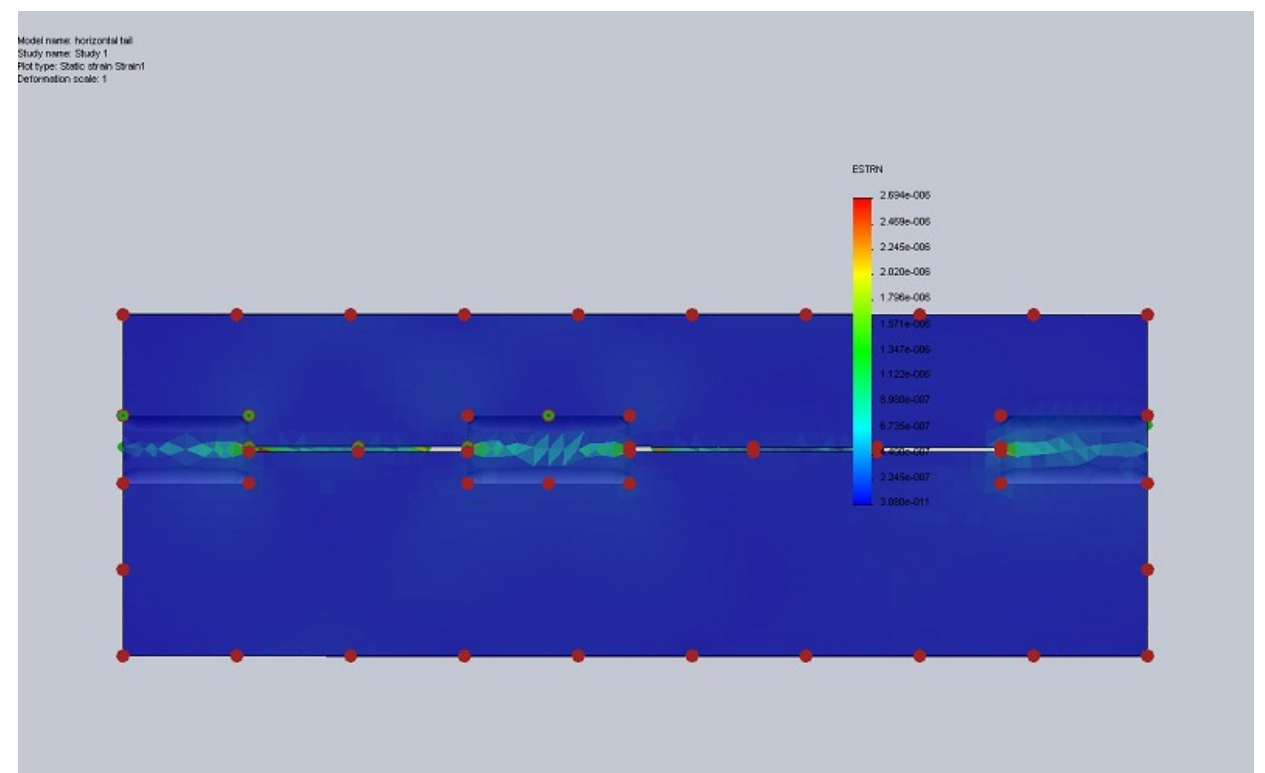

Figure 8: static strain analysis of horizontal tail

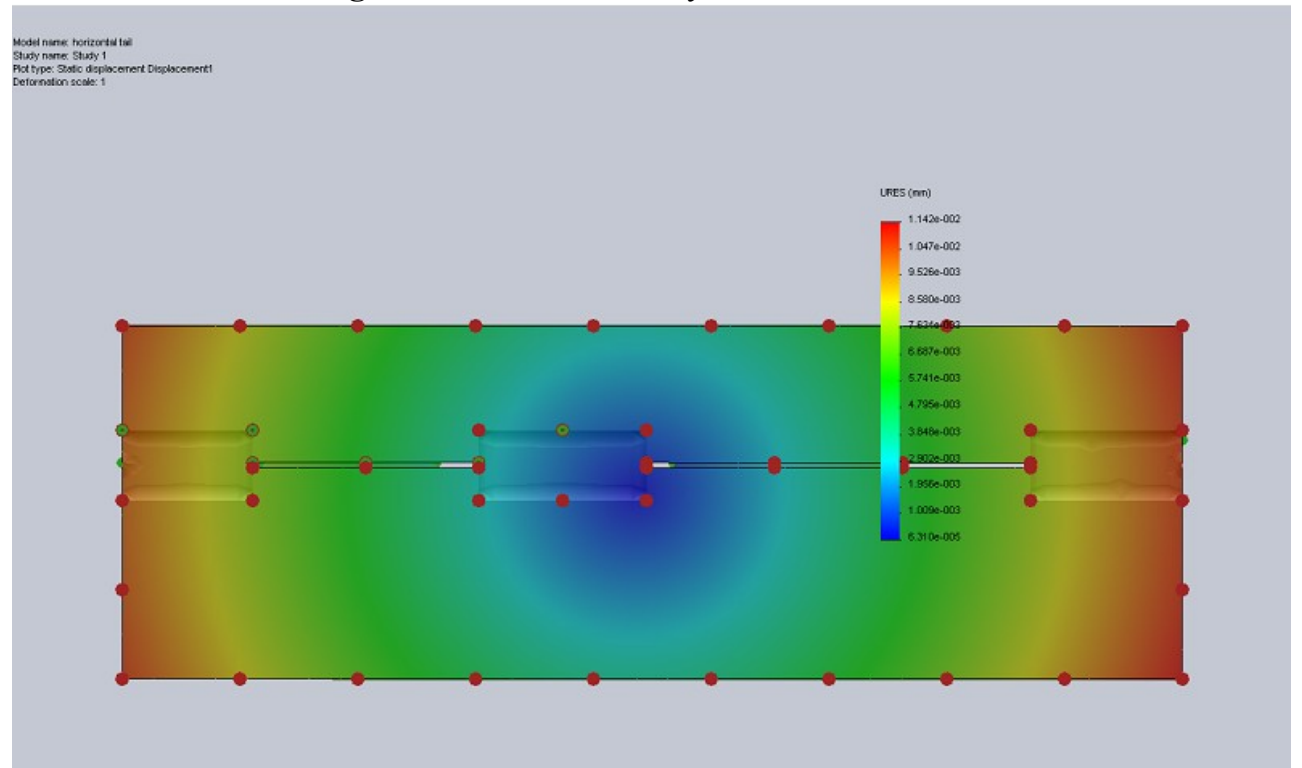

Figure 9: static displacement analysis of horizontal tail

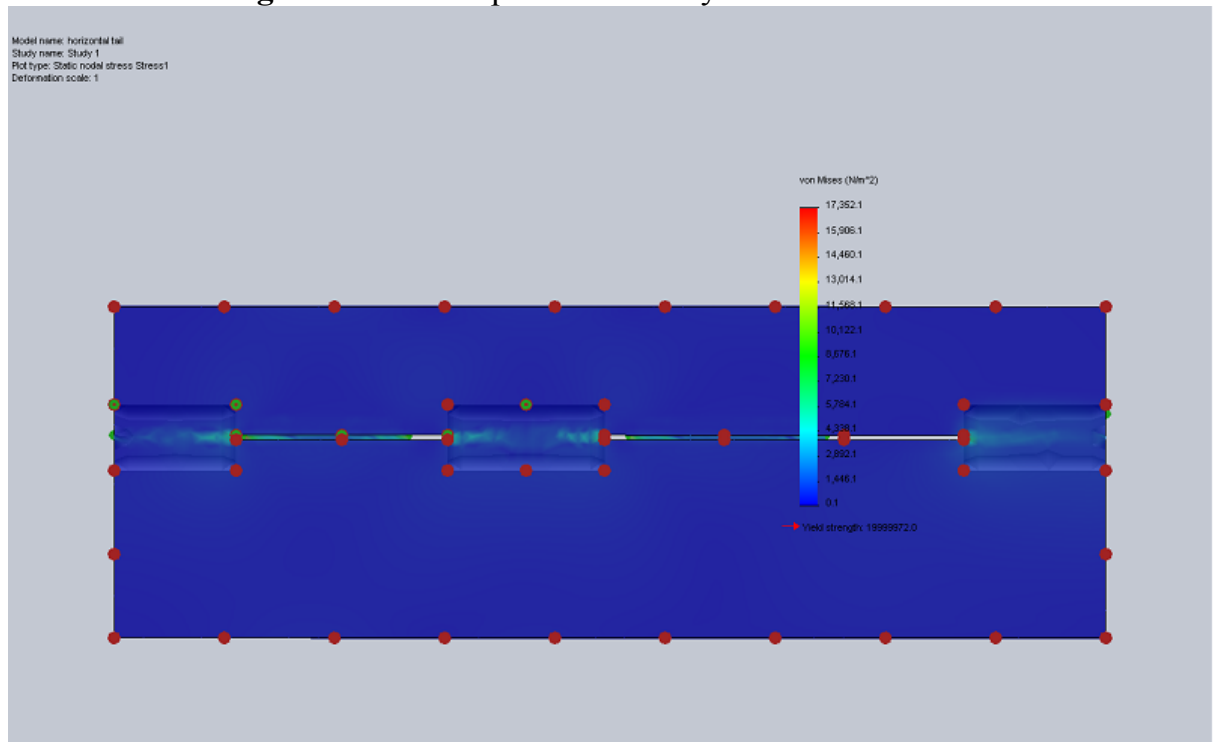

Figure 10: static nodal stress analysis horizontal tail 


\section{Conclusion:}

This work shows the design of an air vehicle by the help of solidworks design is coherently summarized. First the basic design methodology is outlined. Then feature modeling is presented as the core of 3D design technology platforms. Towards fast and accurate aircraft simulation, numerical integration and parallel computing techniques are depicted as the numerical engine in the design platform. The meshing has been done as fine mesh. Load is taken the same for every simulation. Fixing the edge had done on the basis of real prototype. Here the simulation of all parts couldn't be shown due to some reason. Future work can improve the strain, stress capacity of prototype.

\section{Acknowledgement:}

This work has been mainly done as the thesis for completion of level -4 Aeronautical Engineering, Military Institute of Science \& Technology \& also for participating in SAE Aero Design -2013 (west). Thanks go to Nepal Chandra Chattopadhay for helping on writing this paper. The authors of this paper were the prime members of SAE Aero design team -2013 from Military Institute of Science \& Technology. Design mainly done by Md. Shaiful Islam other members assists him to do it better.

\section{Reference:}

[1] Grasmeyer, J.M. - Keennon, M.T: Development of the Black Widow Micro Air Vehicle, AIAA-2001-0127

[2] MacRae, A.: BEng Final Year Project Interim Report, University of Glasgow, 2005.

[3] Mueller, T. J. - DeLaurier, J. D.: Aerodynamics of small vehicles, Annu. Rev. Fluid Mech. 2003. 35:89-111.

[4] Bohorquez, F. et al. Design, Analysis and Performance of a Rotary Wing UAV, Smart Structures Laboratory, Alfred Gessow Rotorcraft Center, Department of Aerospace Engineering, University of Maryland 